Cadernos de História, Belo Horizonte, v. 22, n. 37, Novembro de 2021

DOI: https://doi.org/10.5752/P.2237-8871.2021v22n37p165-183

\section{SER TÉCNICO DA SELEÇÃO É SER POLÍTICO? O CONCEITO \\ DE TREINADOR NOS JORNAIS \\ NACIONAIS, NAS PRIMEIRAS NOVE \\ COPAS DO MUNDO}

Filipe Mostaro

Universidade do Estado do Rio de Janeiro

filipemostaro@hotmail.com

\title{
RESUMO
}

Este artigo tem como objetivo apresentar o percurso histórico do conceito de treinador da Seleção Brasileira, durante as Copas do Mundo de 1930 a 1970. O foco desta pesquisa foi observar como as interações entre os campos esportivo e político se evidenciaram nas narrativas que projetaram um mundo, exigindo determinados atributos dos técnicos de futebol. Foi testada e confirmada a hipótese de que, na narrativa proposta por cinco jornais brasileiros, o "perfil" ideal de treinador e seu conceito atenderam aos interesses da "elite" nacional. Por mais que o conceito se alterasse, indicá-lo como modelo de "líder" foi uma constante, alterando apenas o que era exigido desse personagem a cada competição. Da estreia da seleção até o dia do desembarque da delegação no Brasil, foram selecionadas todas as reportagens dos jornais que abordam o tema Seleção Brasileira. Em seguida, notícias que abordam a figura do treinador também foram analisadas, indicando qual foi o espaço e os conceitos destinados a esse personagem no mundo dos jornais. Através de uma Análise Crítica das narrativas, foram analisadas 2.351 notícias sobre a seleção, sendo que 577 abordavam o treinador.

Palavras-chave: Narrativas; treinador; Seleção Brasileira; Copas do Mundo; conceito

Recebido em 27 de outubro de 2020.

Aprovado em 13 de novembro de 2020. 
Cadernos de História, Belo Horizonte, v. 22, n. 37, Novembro de 2021

DOI: https://doi.org/10.5752/P.2237-8871.2021v22n37p165-183

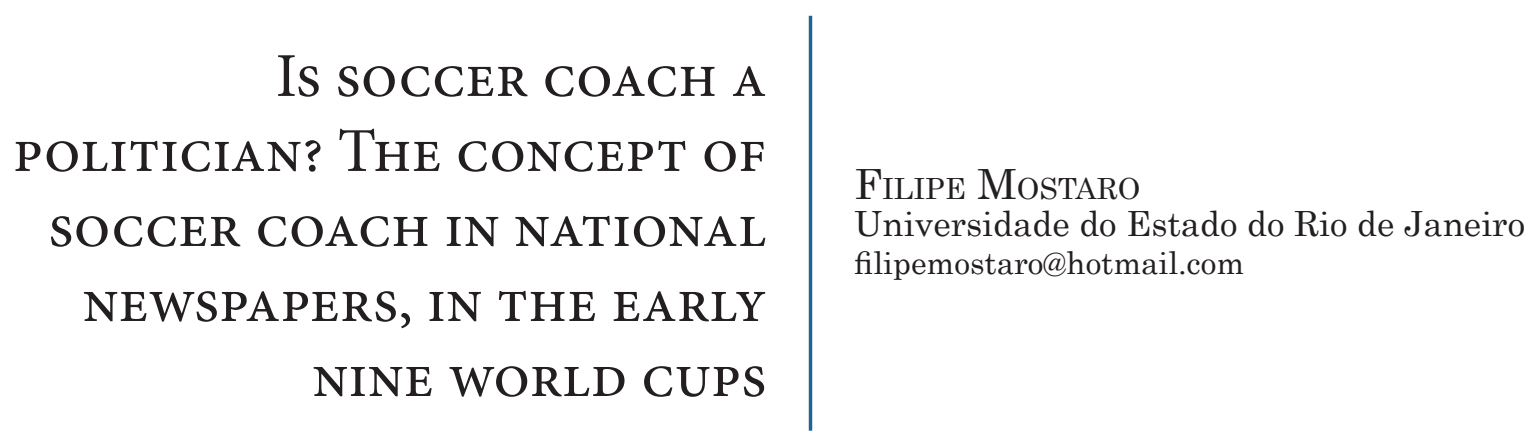

\begin{abstract}
This article aims to analyze the historical path of the concept of soccer coach of the Brazilian football team, during the World Cups from 1930s to 1970s. It focused on to observe how the interactions between sports and political fields evidenced in the narratives that "created a world" requiring some attributes of this coach. It was tested and proved the hypothesis of which narrative proposed by five Brazilian newspapers, the model of coach and its concept were concerning interests of the national "elite". Although the concept changed, indicating it as a "leader" model was a constant, changing only what was required from this character at each competition. From the premiere of the Brazilian soccer team to the day of the delegation's arrival in Brazil, all reports about this team were selected. Then, news about the coach were analyzed, emphasizing what was the space and concepts related to this character in the world of newspapers. Through a Critical Analysis of the narratives, 2.351 news reports were researched, of which 577 approached the coach.
\end{abstract}

Keywords: Narratives; Coach; Brazilian soccer team; World Cups; concept. 


\section{INTRODUÇÃo}

Ser técnico da Seleção Brasileira é também ser político? Partindo desse questionamento, este artigo teve como objetivo apresentar as interações entre os agentes dos campos esportivo e político evidenciadas nas narrativas sobre o técnico da seleção em cinco jornais brasileiros ${ }^{1}$. A pesquisa é um recorte da tese de doutorado defendida no Programa de Pós-Graduação em Comunicação da UERJ, em fevereiro de 2019, que analisou "qual o mundo" os jornais do corpus criaram ao falar sobre o treinador ${ }^{2}$. Foram 2.351 reportagens analisadas, dentre as quais 577 mencionavam os técnicos da seleção, em exatos 200 dias que compreenderam as primeiras nove Copas do Mundo $^{3}$ (1930 a 1970).

Acreditamos que pensar o fenômeno esportivo é também refletir sobre suas interações com outros campos para entender sua complexidade e a produção de sentidos dessas interações em outras esferas. Mais especificamente, nota-se que a Comunicação presente no futebol é poderosa: suas simbologias, interpretações, reapropriações, rituais e criação de mitos e heróis, tornam as manifestações em torno desse esporte um ponto de encontro dos imaginários sociais, de seus dilemas, de seus conflitos e congruências ${ }^{4}$. É, por conta de seu capital simbólico, um meio de propagação de ideologias, como Melo et al. (2013) interpretam. Segundo Motta (2013), a cada edição da Copa do Mundo de futebol, encontram-se "modelos ideais", exigidos pelos jornais brasileiros dos treinadores da seleção brasileira de futebol que atendem a determinados grupos sociais, através das narrativas jornalísticas

Para se interpretar essas interações, foi testada a seguinte hipótese: o técnico da seleção brasileira de futebol seria o representante da elite nacional na narrativa sobre o país que a Copa do Mundo suscita. Buscou-se compreender qual o habitus (Bourdieu, 2004) exigido do indivíduo que ocupa o cargo de treinador da seleção. Ele cumpriu a função exigida pelos jornais no frame Copa do Mundo? Esta análise se iniciará apresentando um "mapa tático", indicando as opções teóricas usadas nesta investigação. Em seguida, em virtude das limitações de espaço que um artigo estipula, serão apresentados os principais resultados da pesquisa que ajudarão a compreender como a interação entre campo esportivo e político, presente no corpus, construíram conceitos desta personagem no "mundo" dos jornais (KOSELLECK, 1992, p. 134-146).

\section{Mapa tático}

A partir do que teoriza Motta (2013), é lícito dizer que as narrativas apresentadas nos jornais sobre o objeto em questão são o "mundo" que os jornais criaram, exaltando características que a elite entendia como "fundamentais" para o "perfil ideal do cargo". A atuação do treinador, que seria algo plural, repleta de detalhes e ressignificações é singularizada pelo "mundo dos jornais", que reproduzem e legitimam a ideia de uma elite. De acordo

\footnotetext{
1 Foram analisados 3 jornais a cada edição da competição: O Globo e Folha da Manhã/Folha de São Paulo (1930 a 1970), fixos na pesquisa e A Noite (1930/1934/1950), Diário de Pernambuco (1938) e Jornal do Brasil (1954 a 1970). Todos os jornais citados estão disponíveis para acesso on-line.

2 A versão final da tese pode ser encontrada na lista de referências deste artigo.

3 Da estreia da seleção até o dia do desembarque da delegação no Brasil, foram selecionadas todas as reportagens dos jornais que abordam o tema Seleção Brasileira. Em seguida, foram analisadas as notícias que abordam a figura do treinador, indicando qual foi o espaço e os conceitos destinados a esse personagem no mundo dos jornais.

4 Cf. Guedes (1998); Helal (2001); Souza (2008).
} 
com Goffman (2012), os indivíduos que assumiram essa função no frame Copa do Mundo podem ter - e têm - outros atributos, porém estes ficaram "à sombra” da narrativa por não se coadunarem com o imaginário desta elite. É sabido que existem outras narrativas sobre os treinadores, entretanto, para o corpus, foram selecionados jornais como Folha e O Globo, por se considerar que tais veículos são reprodutores de narrativas de campos hegemônicos durante toda a sua existência, tornando sua análise decisiva e congruente aos objetivos já expostos neste trabalho. Não foram feitas interpretações a priori, deixando a arena de disputas, que é a narrativa sobre a Copa do Mundo, serão abordados os conceitos.

Norberto Bobbio (1992) destaca que, em uma sociedade, existe uma minoria que, por várias formas, é detentora do poder. Como afirma Mosca (1975), essa minoria seria um estrato da sociedade, que cria condições para exercer esse poder em determinados campos. Esse extrato pode possuir membros de diferentes grupos e campos que se alinham, ora por submissão, ora por interesses mútuos, ora por posição estratégica para produzir, manter ou ajustar a visão de mundo que seja vantajosa para esses indivíduos e seus grupos. A elite seria o resultado das complexas interações e interesses comuns entre esses estratos, ajustados a cada contexto. Entende-se o conceito de elite, nesta pesquisa, não apenas como relações de dominantes e de dominados em cada frame social, mas também como uma narrativa hegemônica, expandida pelos meios de comunicação, que molda um mundo e pretende ampliar um modelo de sociedade com suas próprias regras ${ }^{5}$. O pensamento político brasileiro, por exemplo, passa por essa questão da elite, da formação de narrativas para definir e interpretar o Brasil, como Brandão (2007) e Souza (2015) enfatizam. Essa elite vai elaborar e fortalecer instituições sociais, como a Confederação Brasileira de Desportos (CBD), por exemplo, legitimando seu poder simbólico e garantindo sua hegemonia no campo esportivo.

Neste sentido, o conceito de habitus de Bourdieu (2004) foi fundamental nesta análise. Esse habitus englobaria, por exemplo, as atitudes efetivas do indivíduo nos rituais cotidianos, que lhe darão o capital simbólico exigido pelo campo. O habitus foi determinante para superar uma dicotomia que poderia fornecer a impressão de que, ou o agente do campo estaria livre para suas ações, ou preso às regras de cada contexto social. Assim, a moldura social e a ação do indivíduo não são excludentes. Ou seja, o treinador pode, e fugiu em algumas oportunidades das características pretendidas pelo mundo projetado pelos jornais, como o caso de Feola em 1966, com consequências que se verá adiante. Desse modo, as práticas não são automaticamente reflexo do habitus e sim da interação entre este habitus e as circunstâncias, o contexto social, isto é, o frame de atuação.

Assim, para responder se os técnicos "foram políticos" no mundo dos jornais, foi possível observar como as ações dos agentes dos campos (Bourdieu, 2004) políticos e esportivos contribuíram na elaboração dos "conceitos" sobre o treinador. Ao considerarmos que tais narrativas não são ingênuas, interpretamos os conceitos sobre essa personagem

5 A narrativa funciona como um processo de constituição de realidade, articulando vários elementos para formar significados. Ela cria mundos em associação com o imaginário, por exemplo, configurando relações de poder e disputas pela interpretação de cada sentido. Como Motta (2013) destacou, existe uma série de fatores que legitimam o processo narrativo. A partir da compreensão da narrativa de Motta (2013), destacamos que o jornalismo vai elaborar o perfil dos técnicos selecionando apenas alguns atributos, o que para nós, seriam os desejados pela elite. Assim, as narrativas dos meios de comunicação que compõem o corpus são um dos fatores que estruturam o que chamamos de elite e não a sua totalidade. Seu papel é importante, mas não define arbitrariamente a elite. Ela é uma das varáveis nesta interação, mas não a única e, neste trabalho, foi a variável escolhida para nossa investigação. 
como construções sociais que dialogam com determinados contextos. Como Koselleck (1992) destaca, o conceito ganha novas conotações de acordo com a experiência histórica: "a palavra pode permanecer a mesma (a tradução do conceito), no entanto o conteúdo por ela designado altera-se substancialmente" (Koselleck, 1992, p.138).

\section{OS PRIMEIROS MOVIMENTOS: COPAS DE 1930 E 1934}

Acreditamos que a Copa de 1930 foi um capítulo importante do embate entre paulistas e cariocas pelo controle do futebol nacional. Duas entidades CBD e APEA (Associação Paulista de Esportes Atléticos) representaram cada estado neste conflito. O principal desdobramento foi a não ida dos atletas paulistas à competição ${ }^{6}$.

Encontramos 90 notícias sobre a seleção, das quais 18 mencionavam o técnico. Coube ao ex-jogador, Píndaro de Carvalho, a missão de ser o treinador da seleção na primeira Copa do Mundo. Suas ações diplomáticas em eventos que reforçavam o simbolismo da competição, como um jantar com o então presidente da FIFA, Jules Rimet, por exemplo, ganharam destaque. $\mathrm{Na}$ narrativa predominante dos jornais, Píndaro foi também um agente do campo político, reforçando a intenção da CBD de se afirmar como entidade principal do país frente às outras federações e à FIFA. Convites a clubes internacionais para visitarem o Brasil surgem como um estreitamento das relações entre os países, destacando o futebol como objeto importante nos vínculos internacionais ${ }^{7}$. O jornal $A$ Noite, destaca que a participação brasileira na competição se dava por manter "as melhores relações de cordial fraternidade com o país vizinho (Uruguai)” (A NOITE, 1930, p. 15).

Os três jornais (ver nota 1), ao noticiarem a derrota por 2 a 1 contra os iugoslavos, aproveitaram para destacar o conflito entre APEA e CBD. Por mais que a figura de Píndaro de Carvalho não surgisse nas explicações para a derrota, o jornal $O$ Globo indicou um ponto interessante na interpretação do significado do treinador. Explicando o fracasso da equipe com a "mesquinhez" da APEA, que negou seus jogadores, o periódico reforçou que os pedidos da entidade paulista eram absurdos, principalmente o de "ser o árbitro definitivo na escalação dos nossos scratches" (O Globo, 1930, p.7). Este conflito surgiu como um ponto fundamental para nossa análise: a escolha de quais jogadores representariam a nação. Dominar e controlar esta função era poder projetar uma equipe com a maioria paulista ou carioca, sugerindo uma maior "qualidade" de determinado estado sobre o outro no campo esportivo, o que poderia ser utilizado em outros campos.

Apesar de contar com jogadores amadores e ainda não conseguir produzir uma narrativa coesa de representação nacional, entendemos que a seleção brasileira se tornou objeto de disputas entre campos que divergiam no contexto nacional. Obter a legitimidade do discurso que seriam os "reais representantes da pátria" em um esporte já consolidado como uma manifestação cultural de grande apelo popular e que se enraizava no imaginário nacional, era uma posição almejada pelos dirigentes de Rio e São Paulo . Assim, o "conceito" sobre nosso objeto permeou uma posição política (participando dos eventos diplomáticos e

6 Para maior detalhamento dessa disputa de narrativas entre os jornais paulistas e cariocas durante a Copa do Mundo de 1930, ver: MOSTARO (2016).

7 Para mais detalhes sobre as relações entre CBD e as federações vizinhas, ver Sarmento (2013).

8 Aqui é importante ressaltar que em nenhum momento se cogitou convocar atletas de outros estados. A ideia de que

Rio e São Paulo sintetizavam a nação é evidente. 
representando o país) e a função de "escalar o time titular" (FOLHA DA MANHÃ, 1930, p.1).

Quatro anos mais tarde, o conflito entre amadorismo e profissionalismo ditou as relações entre o campo político e esportivo9. A querela no campo esportivo se dava entre Rivadávia Corrêa Meyer ${ }^{10}$, então presidente da AMEA (Associação Metropolitana de Esportes Atléticos) e Arnaldo Guinle, ex-presidente da CBD e figura importante no campo esportivo nacional. $\mathrm{O}$ campo político influenciou de maneira determinante o conflito entre esses setores e, consequentemente, a narrativa sobre o treinador da seleção em 1934, Luiz Vinhaes.

Durante a disputa de bastidores, a figura de Luiz Aranha ${ }^{11}$ foi crucial. Souza (2008) afirma que, com influência política clara, Aranha foi convidado por Rivadávia para o quadro social do Botafogo. Aranha foi decisivo na Assembleia Geral da CBD (realizada em junho de 1933), em que foi aprovado um estatuto, contrário às posições de Guinle, decidindo que o conselho administrativo, presidido pelo próprio Aranha, teria mais poderes que o presidente da entidade. Com isso, a equipe enviada para a Itália estaria sob influência direta de Aranha.

Vinhaes teve uma participação tímida nos jornais, das 57 reportagens sobre a seleção, 11 mencionavam o "competente técnico" (A NOITE, 1934, p.8). A atuação política ficou a cargo do, considerado pelos jornais, nosso segundo treinador: Carlito Rocha, membro do Botafogo e ligado ao Aranha. Foi uma decisão claramente política e que atendia aos interesses da elite, que controlava o campo esportivo naquela ocasião. É interessante destacar que Vinhaes, apesar de estar no comando da seleção desde 1931, teve, na condição de sua "divisão de tarefas", a permanência no cargo para a competição ${ }^{12}$.

Mesmo com a derrota no primeiro jogo por 3 a 1 contra e Espanha, que eliminou a equipe da competição, os três jornais se preocuparam mais com a resolução da questão do profissionalismo que se desenrolava no Brasil do que com a participação do time na Copa de 1934. Para Souza (2008), a "missão diplomática" de representar o Brasil nos torneios internacionais teve no denominado "fracasso" de 1934 e na "desorganização" que culminou com o envio de duas delegações aos Jogos Olímpicos de Berlim, em 1936, elementos determinantes nas ações que levariam o governo a interferir diretamente no esporte nacional para controlá-lo e, consequentemente, profissionalizá-lo. É importante ressaltar que essa profissionalização, longe de uma ideia de "livre mercado", foi legalizada para estabelecer

9 Para uma melhor compreensão destes conflitos, ver: Souza (2008) e Proni (2000)

10 Segundo Souza (2008), Rivadávia foi o dirigente na conquista da Copa Rio Branco de 1932 e conseguiu a presidência da AMEA no mesmo ano, com o apoio dos clubes menores. A reação imediata dos grandes clubes que formavam o conselho fundador: Fluminense, Vasco, Flamengo, América, Bangu, São Cristóvão e Botafogo foi alegar uma diminuição na renda dos jogos por conta do número excessivo de jogos e pedir uma diminuição dos clubes no campeonato. A proposta era um torneio com os sete fundadores e apenas um dos “pequenos”. Rivadávia implementou sua proposta com 12 clubes, agradando os pequenos e Guinle informou que o Fluminense criaria uma nova Liga. Neste embate, Rivadávia tinha o apoio do Botafogo, clube que era sócio, Flamengo e São Cristóvão. Guinle contava com os demais clubes, com a CBD (presidida por Renato Pacheco) e com uma boa relação com a APEA. Em 1933, Guinle fundou a LCF (Liga Carioca de Futebol). Quatro meses depois, o Flamengo entrou para a LCF, seguido do São Cristóvão no mês seguinte, enfraquecendo o grupo de Rivadávia.

11 Luiz Aranha era amigo pessoal de Vargas. De acordo com Souza (2008), com uma habilidade para a articulação política e irmão de Oswaldo Aranha (figura política destacada nos anos 1930 e ministro da fazenda na ocasião), assumiu vários cargos esportivos ao longo da carreira.

12 Vinhaes, na época com 35 anos, tinha vencido o campeonato carioca de 1926 como técnico do São Cristóvão e foi o treinador campeão do primeiro torneio da LCF, dirigindo o Bangu em 1933. Não seria conveniente para a CBD manter no cargo o técnico que fazia parte de uma equipe da liga comandada por outro grupo político. 
um limite no poder de barganha dos jogadores, que estava crescente. Assim, se indicou a formação de uma legislação que prenderia os jogadores aos clubes, através do chamado "passe" e determinava o teto salarial, combatendo a prática do "profissionalismo marrom", que, a grosso modo, consistia em empregar jogadores nas empresas e comércio dos sócios do clube para que pudessem ser "liberados" para treinar no horário estipulado pelo clube.

$\mathrm{Na}$ elaboração de uma narrativa política que engendrava uma busca pela valorização de manifestações culturais descritas como "nacionais" e com grande apelo popular, como o futebol, por exemplo, a associação entre campo esportivo e político se intensificou. Para Costa (2006), a pacificação e controle do campo esportivo se tornou essencial para a projeção da seleção representar a nação. Sem conseguir conter o profissionalismo, o Brasil seguiu o modelo inglês (LEVER, 1983): a compensação da elite por aceitar jogadores profissionais foi deter o controle administrativo do futebol. O profissionalismo foi reconhecido em 1937, cessando as disputas entre federações, o que possibilitou a elaboração de uma narrativa de uma equipe "realmente nacional", com a presença de todos os atletas considerados "os melhores".

\section{8: UM MOVIMENTO-CHAVE}

Consideramos que a profissionalização vai modificar o conceito de técnico no Brasil. Caldas (1990) enfatiza que a crise no modelo amador e a adoção do profissionalismo atenderam a novas demandas dos grupos que obtinham o controle no campo econômico (maior renda com os jogos), campo social (a narrativa do trabalho e disciplina como algo essencial ao avanço da nação) ${ }^{13}$ e política, que ao controlar tais ações, por meio dos dirigentes amadores e indicados pelo governo na CBD, teria, sob sua tutela, a escolha daqueles que melhor "representariam o de país". O conceito de treinador, antes com papel diplomático nas competições internacionais, atendendo aos interesses da elite nacional, que dominava o campo esportivo e pregava uma visão amadora, se transformou.

Wagg (1984) sugere que no período de profissionalização do futebol na Inglaterra, a função do treinador se modifica para um mediador na luta de classes, sendo a ponte entre capital e trabalho. Foi o que também encontramos nas narrativas dos jornais brasileiros. $\mathrm{O}$ técnico teria o contato direto com os trabalhadores, tiraria os dirigentes da linha de frente dos conflitos e ainda seria o responsável para "organizar o time para a vitória" ${ }^{14}$. Essa posição serviria aos interesses da elite e, em caso de derrotas, seria o "culpado", mantendo a estrutura superior a ele praticamente intacta. Essa configuração será mais clara na Copa do Mundo de 1938, tendo Adhemar Pimenta como representante da elite cultural, que disciplinaria, treinaria e levaria a nação à vitória.

Foram $256{ }^{15}$ reportagens encontradas sobre a seleção e 71 sobre Pimenta. A distribuição das notícias foi mais personalista do que nas outras competições, focando em três pessoas: Leônidas da Silva, Domingos da Guia e Adhemar Pimenta. Para nós, tal importância designada a Pimenta foi emblemática. Foi a primeira vez em nosso corpus que o treinador dividiu o

13 Aqui é importante ressaltar a Consolidação das Leis Trabalhista, durante esse período. Getúlio afirmava que "As leis trabalhistas são de harmonia social” (VARGAS apud GUTERMAN, 2009:71).

14 Cf. Carter (2006)

15 Acreditamos que esse volume de notícias auxiliou na construção da competição como um ritual nacional, elevando importância e o significado da Copa do Mundo nas narrativas sobre o país. Por esses aspectos interpretamos a competição como o nascimento da ideia "país do futebol". 
espaço nas notícias com os atletas considerados "os melhores". Era Adhemar quem falava à imprensa diariamente. Foi a terceira maior porcentagem em relação às notícias da seleção que encontramos no corpus, $27 \%$.

A narrativa sobre Pimenta reforçava o caráter disciplinador do técnico e sua função na formulação de estratégias para a vitória, como este trecho ilustra: "preparador, organizador e orientador da equipe: Pimenta” (DIÁRIO DE PERNAMBUCO, 1938, p.5). A ideia de disciplinar os atletas era uma preocupação de Vargas: "O presidente Getúlio Vargas acompanhou no rádio, do Palácio Guanabara, todas as fases do jogo Brasil-Polônia, mostrando entusiasmo pela vitória do selecionado e pela maneira como os craques nacionais souberam acatar as decisões do juiz" (DIÁRIO DE PERNAMBUCO, 1938, p.1). Não seria leviano associarmos a narrativa de um grande líder na seleção com a narrativa de um grandioso comandante decantada pelo Estado Novo. Aliás, foi a primeira vez em nossa investigação que o termo "comandante" foi usado para se referir ao treinador da seleção. O técnico Adhemar Pimenta "convocaria" os atletas e não os chamaria para integrar a seleção. Para Souza (2008), os sentidos de convocação, semelhantes aos do campo militar ${ }^{16}$, indicam uma relação vicinal entre tal campo e o esportivo, nesse contexto. Atendendo aos interesses da elite na época, a "maneira militar" era posta como a correta para ensinar e disciplinar. O conceito de treinador dialoga com o contexto, posicionando Adhemar como um representante das forças políticas que constituíam o Estado Novo.

\section{E 1954: O REFORÇO DA DISCIPLINA}

A criação do Conselho Nacional do Desporto (CND), em 1941, simbolizou a efetivação do controle do esporte nacional pelo Estado e também revelou a importância simbólica que o esporte alcançava ao ser inserido no campo político de forma oficial. Com a ideia de controlar e disciplinar em voga, o CND seria dirigido por uma comissão de cinco membros escolhidos diretamente por Vargas. Tal ação indica que a elite da época estaria presente nas decisões que envolviam esse fenômeno cultural. Portanto, a posição de disciplinador do conceito de “técnico" da seleção se manteve nas narrativas dos jornais durante as Copas de 1950 e 1954.

Sediar a competição entrou no imaginário nacional como o "passaporte" para a Modernidade. O campo esportivo se associou a outros campos, como econômico, político, social e midiático nesse processo narrativo. A atmosfera encontrada nos jornais $A$ Noite e $O$ Globo era de que a vitória na competição concretizaria esse "avanço" da nação. A organização e disciplina eram os atributos mais enfatizados nessa narrativa e dialogavam diretamente com o campo político. Nesse viés, Flávio Costa, técnico da seleção, vai agrupar tais virtudes exigidas pela elite.

Encontramos 176 reportagens sobre a seleção e 47 que mencionaram Flávio Costa. $O$ Globo, cumprindo seu papel de projetar o mundo da CBD, enfatiza que as atitudes da entidade com a competição foram corretas, elogiando a disciplina e autoridade de Flávio Costa:

Primeiro credenciando um treinador e, depois, outorgando ampla autoridade e esse treinador, para fazer a escolha dos elementos. Flávio Costa foi o nome apontado pela unanimida-

16 Carter (2006) destaca que o modelo "sargento do exército” para o treinador também foi visto na Inglaterra, implantando uma estrutura de administração similar ao das forças armadas. Nesse sentido, a experiência no controle de um grande grupo de homens foi levada para o campo esportivo. As figuras "sargentões", que gostam de fazer as coisas do seu jeito, através do autoritarismo verbal, foi amplamente explorada também no futebol. A "gestão pelo medo" se tornou institucionalizada em grande parte no futebol britânico, influenciando a formulação da ideia do "boss" (chefe). Ideais de coragem e lealdade ao clube passam a ser mais exigidas como o "amor à pátria" e o "amor à camisa". 
de das consciências. E consequentemente aceito. Mas uma vez empossado, também Flavio começou a agir, estabelecendo um amplo e criterioso programa de atividades (O GLOBO, 1950, p.1).

No quadrangular final, Flávio dividiu as atenções com Ademir e Zizinho. Seu papel de porta-voz, ao dar entrevistas diariamente, se torna mais nítido. As notícias sobre os treinos foram mais frequentes no corpus, confirmando a ideia de organização e disciplina. A vitória de 7 a 1 sobre a Suécia impulsionou o capital simbólico de Flávio. No dia seguinte, o entrelaçamento campo político e esportivo se torna evidente. O jornal $O$ Globo foi mais "romântico" ao anunciar que o treinador brasileiro seria candidato a vereador:

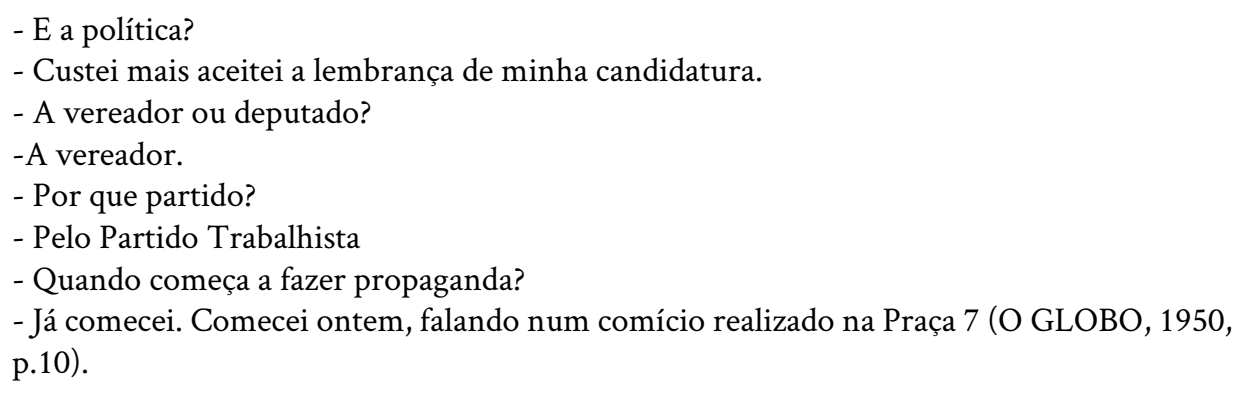

O treinador já havia começado a campanha, utilizando a atmosfera da competição para catapultar sua influência para o campo político ${ }^{17}$. A Folha da Manhã, no parco espaço que destinava à seleção, também noticiou, no caderno de política, que "Flávio é candidato a vereador, pelo Distrito Federal” (FOLHA DA MANHÃ, 1950: 7).

O imaginário de consolidação de um "país grande" através do futebol é negado com a vitória do Uruguai ${ }^{18}$. Entretanto, como membro da elite, Flávio foi visivelmente poupado nos jornais investigados, mantendo o conceito de disciplina sobre o treinador. A Noite e O Globo não criticaram o treinador: "Flavio ia e vinha, animando um e confortando outro. Estava pálido, estava triste, mas senhor de si" (O GLOBO, 1950, p.12). Mas isso não significa que seu imaginário de organizador e disciplinador que a seleção e a narrativa da elite consideravam como necessidade era compreendido por outros setores como o "correto". Sua derrota na eleição para vereador sinaliza alguns caminhos interpretativos ${ }^{19}$. O quase vereador e quase campeão do mundo esbarrou na derrota "inimaginável" que seu planejamento não previu e sua disciplina não suplantou.

Se a vitória não veio dentro do campo de jogo em 1950, no campo esportivo ela aconteceu. Sarmento (2013) considera que o sucesso da organização da Copa de 1950 reposicionou o Brasil no campo esportivo mundial. No Congresso da FIFA, realizado no Brasil durante a competição, Luiz Aranha foi indicado como vice-presidente da entidade. O Brasil conseguiu estabelecer uma nova correlação de forças no continente, reduzindo a hegemonia uruguaia e argentina. A disciplina/organização foi o argumento mais utilizado para explicar esse sucesso no campo esportivo e fortaleceu a atuação política da CBD.

17 No O Globo, depois da vitória do Uruguai, encontramos essas duas manchetes: "Gighia para senador; Obdulio Varela para presidente da republica” da United Press. Não seria apenas no Brasil que o simbolismo do esporte ultrapassaria o seu campo e invadiria outras esferas.

18 Destacamos aqui alguns trabalhos que analisam os impactos dessa derrota na narrativa de desenvolvimento nacional: Cf. Perdigão (1986); Araújo Moura (2010); Brinati (2016).

19 Em nosso corpus, não encontramos críticas duras a Flávio Costa. Isso não quer dizer que elas não existiram. O que ficou claro para nós é que no material coletado, Flávio foi poupado das críticas. 
Depois de chegar tão perto da concretização de uma narrativa de "melhores do mundo" e todos os reflexos em outros campos que o título poderia proporcionar, vencer a Copa do Mundo passou a ser a "grande missão" dos dirigentes da CBD. Para isso, elaborar uma narrativa que explicasse a derrota em 1950 se torna fundamental. A CBD investiu em um nacionalismo que recuperaria a moral "abalada", com a pregação de uma doutrina quase que militar de "tudo ou nada" pelo time, que esteve presente nas narrativas dos jornais durante a competição. Começar "tudo do zero", com a "pátria acima de tudo", incluindo a camisa, foi a escolha da CBD. E "mudar tudo que tá aî" começava com a escolha do treinador. O técnico do Fluminense, Alfredo "Zezé" Moreira, foi amparado pelos dirigentes e fez uma reformulação no elenco, com jovens talentos dos times de Rio de Janeiro e São Paulo. Mais uma vez, evidencia-se a solidificação desse eixo como o "resumo" do país.

Sarmento (2013) destaca que a CBD conseguiu uma verba federal de Cr\$ 8 milhões para que a equipe se preparasse durante quatro meses para a competição. A entrevista de Zezé, um dia antes da estreia, indica a preocupação com a parte física e moral dos atletas. "Antes de mais nada, acredito acima de tudo no estado atlético e moral dos nossos homens. São capazes de dar um pedaço de suas próprias vidas para obter um triunfo honroso neste certame" ${ }^{20}$. A reportagem sobre o treinador termina reforçando a disciplina e como os atletas supostamente haviam a incorporado: "É uma brava gente que dá gosto dirigir, aconselhar, pedir sem exigir, porque não se é preciso ir além de um pedido normal" (O GLOBO, 1954, p.1). No dia do primeiro jogo contra o México, a Folha da Manhã ressalta o poder disciplinador de Zezé ao destacar os jogadores como "pupilos de Zezé Moreira”. Essa associação remete ao estilo "sargentão da família", descrito anteriormente.

Foram 152 reportagens sobre a seleção e 45 menções a Zezé Moreira. Foi a segunda maior proporção de notícias sobre o treinador em relação à seleção no corpus: $29 \%$. Analisando a narrativa dos três jornais, inferimos que salvar, reforçar e ampliar o papel da elite era fundamental nessa ressaca e desconfiança com o mito "país do futebol". Após a eliminação nas quartas de final, as manchetes destacaram: "A calamitosa atuação do árbitro, em benefício dos húngaros, influi decisivamente no resultado - 4 a 2, um placar que não reflete o desenvolvimento da peleja” (FOLHA DA MANHÃ, 1954, p.8). "Não perdemos para a Hungria: fomos apenas derrotados por Mister Ellis" (JORNAL DO BRASIL, 1954, p.17). Os jornais associaram a derrota às ações desleais de membros que deveriam cuidar da idoneidade do jogo: o juiz. O projeto da CBD havia sido positivo e só perdeu por "má sorte". Seu representante precisava ser exaltado e, no mundo dos jornais, foi. A narrativa sobre Zezé foi, em linhas gerais, positiva. Ele foi um membro da elite nesse campo, disciplinando os atletas e elevando a moral de "seus pupilos" 21.

\section{A 1970: "Ñ̃o ATRAPALHE NOSSO TALENTo"}

Para Guterman (2009), a busca por uma modernização do país, com o governo de Juscelino Kubitschek, teve na construção da nova capital, Brasília, o resumo do lema de seu mandato: “50 anos em 5". Proni (2000) pontua que é possível estabelecer um paralelo entre 20 Cf. O Globo, 15/06/1954:1.

21 É importante citar outras narrativas que não aparecem em nosso corpus, indicando como a Copa do Mundo é uma arena de disputas. Uma delas foi divulgada pela própria CBD, que explicava a derrota com uma suposta diferença entre europeus (coletivos e disciplinados) e os latinos (individualistas e imprevisíveis) (Sarmento, 2013). Apesar de não surgir de forma clara nos jornais pesquisados, as questões moral e racial também foram postas em outras narrativas como justificativa para a derrota. 
esses "anos de ouro" da seleção com a vida econômica e política da nação. Tivemos, por exemplo, os primeiros passos do "modelo econômico de gestão" do futebol no Brasil. João Havelange assumiu a presidência da CBD em 14 de janeiro de 1958 e implantou um modelo empresarial na estrutura da instituição. A ideia de renovação era clara: "a centralização da gestão esportiva sai de cena para dar lugar a um novo conjunto de gestores, com táticas e objetivos nitidamente distintos" (SARMENTO, 2013, p. 108).

Para auxiliá-lo nesse processo, Havelange nomeou Paulo Machado de Carvalho, dono das rádios Panamericana e Record, além da TV Record, como "chefe" da delegação que iria à Suécia. Carvalho era um agente que detinha um capital simbólico importante nos campos político, esportivo, social e midiático. Essa circulação amistosa influenciou diretamente a cooperação entre os agentes desses campos na formulação da narrativa encontrada nos jornais sobre a seleção brasileira, nas Copas de 1958 e 1962. O que inferimos nessa movimentação, é que o agente não está imóvel em determinada esfera, ele pode exercer influência em mais de um campo, como Carvalho exercia. Assim, a formatação dessa elite se dá nessas interações entre indivíduos que atuam nos campos.

Paulo Machado era visto no mundo dos jornais como um "empresário de sucesso" que forneceria o que faltava à seleção. As narrativas midiáticas destacaram que jamais o Brasil havia se planejado e se preparado tanto para uma competição. Foi Paulo quem escolheu Vicente Feola como treinador. O "perfil ideal" estipulado para o treinador naquela ocasião seria de alguém que aceitaria a interferência externa de uma elite que agora fazia parte da "comissão técnica" e faria a "gestão" direta do "trabalho de equipe". Em suma, no "mundo dos jornais", Havelange e Carvalho foram os homens fortes, ao passo que Feola se tornou o coadjuvante. Porém, vale destacar, com muito menos "cartaz" que os jogadores. Esse trecho do jornal $O$ Globo mostra como a relação CBD e poder político era intensa: "o presidente JK está radiante com o seu colega João Havelange pela vitória do Brasil, confirmando suas declarações de que o Brasil avançaria 50 anos em cinco anos, durante seu governo" (O GLOBO, 1958, p.17). O mundo criado é da relação visceral entre representante da nação e representante da seleção.

Logo no primeiro dia de análise, encontramos uma narrativa no jornal $O$ Globo, que elabora uma nova compreensão do papel do treinador nessa conjuntura:

\footnotetext{
Deve-se esclarecer ao público, que não é o técnico que escala sozinho a equipe, embora, de um modo geral, venha prevalecendo a sua opinião. Os outros, frise-se, na pior das hipóteses tem colocado o seu aval nas recomendações de Feola e se na vitória final ou parcial não estiver no "script", tenham certeza os leitores de que a responsabilidade está dividida entre Feola mesmo, Carlos Nascimento, Paulo Amaral, José de Almeida e Hilton Gosling, com ligeiras sobras para o chefe Paulo Machado de Carvalho e alguns de seus colaboradores diretos (O GLOBO, 1958, p.3).
}

Interpretamos como uma defesa dessa "nova gestão", inclusive ao destacar a importância dos jogadores se adaptarem a um "bem maior" e de enquadrar Feola como o "homem certo no lugar certo”. A Folha, em seu editorial logo após o título, destaca:

O resultado final de domingo teve ainda o mérito de revelar que somamos ao apego brasileiro ao futebol e às inegáveis habilidades individuais dos nossos atletas, outros fatores indispensáveis de triunfo: disciplina, conjunto e boa organização. Sabe-se que a improvisação, o estrelismo e a rebeldia sacrificaram, numerosas vezes, as nossas aspirações ao título mundial (FOLHA DA MANHÃ, 1958, p.1). 
Nessa linha, enfatizar que a imposição do talento nacional só foi possível por conta da organização da comissão (vinda da elite) foi a "arma" dessa elite ao adaptar sua narrativa a algo inegável e reconhecido pelos outros países: o talento. Feola teve 85 menções das 401 reportagens sobre a seleção. Os três jornais o destacaram Feola como aquele que era "paciente" e deu as condições para os jogadores "jogarem seu melhor futebol”. Feola foi exatamente o "modelo ideal" que a elite pretendia, "jogando o jogo político", proposto pelos agentes do campo, como o seu "chefe" Paulo Machado de Carvalho. O conceito de treinador dialoga com a exaltação do talento e emerge a ideia de que sua principal função era não atrapalhar esse talento. Em resumo, a narrativa sobre a Copa de 1958 exaltou a disciplina e organização da comissão técnica, inaugurando uma ideia de "modelo empresarial" com pessoas especializadas em cada setor, colocando Feola à sombra de dois dirigentes.

Todavia, como já ressaltamos, Havelange e Paulo Machado de Carvalho também ficaram à sombra do talento do jogador brasileiro. Essa "Nova Era" colocou o jogador maior que o treinador. A estreia na seleção de Pelé e Garrincha consolidou esse imaginário de tal modo que o "país do futebol" ganharia suas maiores referências e duas faces de uma moeda extremamente valiosa ao capital do campo futebolístico. A simbologia do futebol na nação como espaço para a disputa de imaginários e narrativas teria, com Garrincha e Pelé, a sua "Era de Ouro". Vencer três Copas em quatro disputadas levou a "organização" para os bastidores, que ainda apareceria ser um atributo da elite, mas focou os holofotes no "talento incomparável" do brasileiro.

Quatro anos depois, a estrutura se manteve e esse conceito foi reforçado. Porém, por motivos de saúde, a CBD escolheu Aimoré Moreira para substituir Vicente Feola. Aimoré era ex-goleiro de futebol e, na ocasião, era técnico da seleção paulista. Irmão de Zezé Moreira, Aimoré já havia treinado a seleção por um período entre as Copas de 1950 e 1954, mas sem sucesso. Aimoré seria alguém já inserido no meio e próximo aos dirigentes da CBD. As menções a Aimoré Moreira indicaram a menor proporção do nosso corpus. Em 1930, por exemplo, tivemos $20 \%$ das notícias sobre a seleção mencionando o treinador da seleção, 19 \% em 1934, 27 \% em 1938, 26 \% em 1950, 29 \% em 1954, 20\% em 1958 e 13 \% em 1962. No mundo criado pelos jornais, Aimoré perdeu para a comissão técnica. A ideia de que o treinador não deveria atrapalhar o talento foi clara nos jornais pesquisados.

Se a narrativa vitoriosa foi, novamente, a do talento nacional, coube aos jornais repetirem a ideia de comissão técnica competente. Das 377 notícias sobre a seleção, Aimoré foi citado de em 51 . O mundo dos jornais também deixou claro seu papel enfraquecido frente ao "chefe":

\footnotetext{
o treinador brasileiro Aymoré Moreira declara que somente hoje, antes da partida, escalará seu conjunto. As informações do preparador nacional, todavia, são contestadas pelo chefe da delegação, Paulo Machado de Carvalho que informou aos jornalistas que não haverá modificações no quadro (FOLHA DE SÃO PAULO, 1962, p.13).
}

As manchetes indicam que quem escalava os jogadores era a comissão: "Comissão quer lançar Amarildo e Belini” (O GLOBO, 1962, p.12). Aimoré foi uma sombra frente aos dirigentes que foram objetos constantes dos holofotes midiáticos. Novamente, as figuras de Carvalho e Havelange foram mais exaltadas durante o bicampeonato. Sarmento (2013) ressalta que uma parte dos jornalistas reconhecia a porção de responsabilidade da CBD 
nas conquistas, explicando-as com a junção talento-estrutura. Dizer que essa elite não tinha nenhuma participação nas conquistas do esporte era perder sua posição em um campo tão importante na elaboração simbólica do que seria o país.

Para Fico (2014), no período seguinte, entre Copas, o país sofreu um golpe militar. Manter o controle na disputa do campo esportivo era fundamental em uma conjuntura de acirramento entre grupos sociais. Os conflitos internos no campo político fizeram com que Paulo Machado de Carvalho deixasse o cargo ${ }^{22}$. Para substituí-lo, o próprio Havelange acumulou funções e se tornou o chefe da delegação. Vencer a Copa na Inglaterra e conquistar definitivamente a Taça Jules Rimet, era uma arma política decisiva para Havelange chegar à presidência da FIFA e implantar o seu modelo de gestão na entidade.

Vicente Feola retornou ao comando da seleção em uma Copa com uma responsabilidade enorme no mundo projetado pelas narrativas. No dia da estreia contra a Bulgária, a Folha indica esse favoritismo: "A equipe brasileira manteve sua condição de preferida dos apostadores como a maior candidata ao título” (FOLHA DE SÃO PAULO, 1966, p.1).

Com a eliminação na primeira, fase as narrativas direcionaram os holofotes para a comissão e para Feola. O "fracasso" de quem teria que organizar, disciplinar e manter a "ordem", algo diretamente ligado ao pensamento dos apoiadores do golpe militar, não poderia ser anexado ao "modelo ideal" dessa elite, que comandava o país na ocasião. Sendo assim, o treinador, que vinha tendo uma queda nas últimas competições quanto a sua importância nas vitórias, se tornou "o" culpado pela derrota. Feola apareceu em 42 das 217 reportagens sobre a seleção, chegando a 19 \%. Para a narrativa dos jornais, a causa da derrota seria o treinador não ter "entendido" as mudanças do futebol mundial, ter preparado mal os jogadores e não definido o time titular, o que contribui para que eles estivessem confusos em campo. Aqui, encontramos a confirmação da proposição de Wagg (1984): na busca por resultados, o treinador de futebol seria o culpado imediato pela derrota, deixando a estrutura acima dele intacta.

Paralelamente a isso, o então ministro da Justiça, Viana Filho, ao divulgar a nova lista de cassados no âmbito do serviço público estadual e municipal e ser questionado se Feola estava na lista, disse: "não está, mas deveria estar, pois técnico, como Peru, se mata de véspera" (JORNAL DO BRASIL, 1966, p.20). O tom sombrio, como as ações militares na época, sancionava uma violência simbólica contra o treinador que quase ocorreu efetivamente. Essa tensão e uma "caça" aos culpados chegou ao técnico e a seus familiares. No dia 20 de julho, reportagens da Folha e do Jornal do Brasil destacam que a esposa de Feola passou a atender chamadas telefônicas ameaçadoras após o fim da partida. A casa seria apedrejada se não estivesse "guardada por dois policiais" (ibid.).

No mundo dos jornais, Feola, que fora "político" em 1958, se tornou "inimigo" após a derrota na Inglaterra ${ }^{23}$. Sarmento (2013) afirma que Havelange e membros da comissão técnica de 1966 passaram a ser acompanhados por membros do SNI (Serviços Nacional de Informações). Após a Copa, havia uma pressão de deputados, com apoio do setor militar, para se abrir um inquérito que explicasse a derrota na Inglaterra e exigisse retratação pública dos jogadores e da comissão. A busca

22 Para melhor compreensão da saída de Paulo Machado de Carvalho do cargo, ver: Sarmento (2013).

23 Com toda a expectativa criada para o tricampeonato, perder não se encaixava no frame sobre a seleção. Assim, o mundo dos jornais "descarta” Feola. A derrota decretava que ele não tinha mais o habitus e perfil necessário para o cargo. A pesquisa completa, que pode ser encontrada no link da nota 1, indica que das nove competições analisadas, 1966 foi a que o treinador teve o maior volume de notícias negativas (14). 
por "culpados" chegava a esse extremo, além de indicar qual o simbolismo da seleção e da competição no imaginário dessa elite. Sarmento (2013) ainda destaca que era uma ideia crescente entre os agentes da SNI que o poder mobilizador do futebol obrigava um monitoramento constante do órgão em sua gestão.

Para esse monitoramento, foi criada a Comissão Selecionadora Nacional (Cosena). A Cosena ${ }^{24}$ definia os assuntos da seleção como escolha do treinador e convocações. Sua formação refletia o embate entre campos para regular a seleção nacional. Com a pressão da derrota em 1966, Paulo Machado de Carvalho voltou a exercer sua influência. Mendonça Falcão, presidente da Federação Paulista de Futebol e deputado estadual entre 1951 e 1969, logo após a derrota em 1966, já indicava em reportagem do Jornal do Brasil que, em 1970, Paulo Machado seria o "chefe" novamente. Essa corrente política bancou Paulo como o presidente da comissão. Com os resultados "fora do esperado", Havelange conseguiu, em 1969, rearticular suas forças dentro do campo esportivo e dissolver a comissão. Faltando pouco mais de um ano para a Copa, Havelange escolheu o jornalista João Saldanha para ser o treinador da seleção.

Saldanha teve uma experiência como treinador do Botafogo em 1957, sendo campeão estadual com um time que teria jogadores importantes na seleção campeã na Suécia, entre eles, Garrincha, Didi e Zagallo. Saldanha era um simpatizante declarado do PCB (Partido Comunista Brasileiro), o que provocava um evidente embate com os membros da ditadura militar. Para nossa hipótese, seria uma rica análise ver um "comunista" comandar a seleção em uma competição que seria palco de intensos debates sobre o país. Entretanto, Saldanha não chegaria até a Copa no cargo. As histórias sobre a demissão indicam um emaranhado de argumentações que, pela atmosfera do país, interpretamos da seguinte forma: ele não era o "homem ideal" da elite, na busca pelo tricampeonato. Para Guterman (2009), iniciou-se uma ideia, frequentemente abordada pelos jornais de que o clima entre jogadores e Saldanha não era agradável. Dando eco a essa declaração, o então Ministro da Educação, Jarbas Passarinho, disse que o clima na seleção era prejudicial à ordem no país.

Havelange tentava blindar Saldanha com a argumentação de que o então treinador tinha forte apoio popular e bons resultados dentro de campo. Entretanto, duas derrotas e um empate deram os subsídios necessários para, baseado nos resultados e no "temperamento forte" do treinador, demiti-lo. Enquanto uma nova comissão recheada de militares era formada, Saldanha afirmou que o motivo de sua saída seria um pedido do então presidente Emílio Garrastazu Médici, para convocar o atacante Dario, o "Dadá Maravilha”. A frase de João: "Você escala seu ministério que eu escalo a seleção" ganhou contornos históricos e indicou o patamar que o cargo de treinador de futebol atingira na sociedade. Saldanha, o popular "João Sem medo", não se encaixou no "modelo ideal" e acompanhou a Copa no banco dos jornalistas, enquanto Zagallo assumiu a equipe.

A ditadura tinha como proposição "arrumar a casa”, "acabar com a bagunça” e "disciplinar

24 De acordo com Sarmento (2013), essa comissão tinha dirigentes de federações subordinados a lideranças políticas nacionais ou representantes de militares e passaram a exercer uma pressão constante sobre a seleção. 
o país”25. Pela primeira vez um militar chefiou a delegação: Brigadeiro Jerônimo Bastos. Com toda essa efervescência entre campos a preparação, disciplina e treinamento vão aparecer com a maior intensidade no corpus. Interpretamos que a exaltação à comissão e sua preparação considerada moderna se harmonizou com o pensamento da elite nacional, simbolizada naquela conjuntura pelos militares ${ }^{26}$. Se o tricampeonato viesse para coroar o "país do futebol", como veio, era necessária uma maior "fatia do bolo" para a elite na "explicação" da conquista. Interpretamos que a presença desta elite foi metaforizada na preparação amplamente abordada de forma positiva no mundo dos jornais. Foram 625 notícias sobre a seleção, 207 sobre Zagallo, o que caracterizou 33 \% do total das matérias. Foi o maior percentual do corpus e o maior volume de notícias, impactados, em nossa interpretação, pela transmissão televisiva.

O papel de Zagallo foi de auxiliar os atletas na conquista e representar a preparação e organização da comissão. Porém, acreditamos não ter sido apenas por este motivo o alto número de citações ao treinador. Zagallo era, ao lado de Pelé, o único remanescente das duas conquistas anteriores. No mundo dos jornais ele era o treinador competente, o exatleta apaixonado pela seleção e exaltador de seu simbolismo, além de ter atributos que se coadunavam ao modelo pretendido pela elite na época. Assim, em 1970, surgiu também uma personagem que foi recorrente nos frames Copa do Mundo, inclusive protagonizando embates interessantes com a própria imprensa. Com a conquista, Zagallo efetivou seu capital simbólico no campo esportivo, fato que o proporcionou participar de comissões técnicas em mais quatro competições $(1974,1994,1998$ e 2006) sendo o indivíduo que mais vezes "comandou” a seleção nas 21 Copas do Mundo. O "técnico do tri” foi um dos fios condutores no ápice da narrativa sobre o "país do futebol" e vai iniciar a nova era dos treinadores em 1974, com a "obrigação" de valorizar essa moeda no "grande mercado" que Havelange, como presidente da FIFA, transformaria a competição.

\section{CONSIDERAÇõES FINAIS}

Em linhas gerais, nossa preocupação foi compreender o processo narrativo projetado pela elite através dos jornais, que elaborou o aspecto simbólico da figura dos técnicos, no frame Copa do Mundo. Consideramos que a ideia desse personagem como um líder dialogou diretamente com o contexto político. Por mais que o conceito se alterasse, indicá-lo como modelo de "líder" foi uma constante, alterando apenas o que era exigido a cada competição. As interações de nosso objeto com o campo político indicaram como essa elite teve o controle da CBD durante esses 40 anos investigados.

Das 2.351 reportagens analisadas no corpus, o treinador foi citado em 577: 1930 (90/18), $1934(57 / 11), 1938(256 / 71), 1950(176 / 47), 1954(152 / 45), 1958(401 / 85), 1962(377 / 51), 1966$

\footnotetext{
25 O governo se empenhava em campanhas ufanistas como "Brasil, ame-o ou deixe-o" e construía uma narrativa de que o país estava no "rumo certo", enquanto aumentava a repressão aos grupos que lutavam pela volta da democracia. Vimos nos jornais imagens de membros da ditadura comemorando as vitórias da seleção e manchetes como essa "Médici participa do entusiasmo do povo" (FOLHA DE SÃO PAULO, 1970, p.1). A declaração do ministro Jarbas Passarinho resume como o governo tentava moldar o imaginário e inserir a conquista como algo diretamente associado à nação, e consequentemente, ao governo: “o tri é afirmação nacional” (FOLHA DE SÃO PAULO, 1970, p. 6).

26 Já ressaltamos que a interação entre os grupos que formam o que estamos denominando como elite é repleto de conflitos. Nesta conjuntura, Fico (2014) ressalta cisões internas que indicavam uma falsa "unidade militar".
} 
$(217 / 42)$ e $1970(625 / 207)^{27}$. Por mais que as menções e citações a esses indivíduos oscilassem entre 33 \% (1970) e 13\% (1962), o conceito de técnico na "realidade social" emoldurada no "mundo dos jornais" percorreu caminhos que se ajustaram a determinadas conjunturas, mas sempre cumprindo o papel desejado pela elite nesse jogo narrativo, confirmando a nossa hipótese. Escavar a superfície das notícias nos indicou a existência de um princípio gerador desse habitus: o imaginário dessa elite.

A própria profissionalização, que modificou o conceito de treinador, foi um ato carregado de influência direta do campo político. As ações profundamente entrelaçadas entre a entidade e os governos em diferentes contextos foram nítidas: a missão diplomática nas primeiras Copas, passando pela criação do CND por Getúlio, que nitidamente exerceria o papel disciplinador no esporte, até as mensagens dos presidentes, que buscavam capturar o capital simbólico das conquistas no campo esportivo para o campo político em 1958 e 1962, por exemplo. Os agentes de ambos os campos se associavam em seus gestos e na formulação do "perfil", que seria exigido nos jornais. $\mathrm{Na}$ ditadura militar, o campo esportivo também foi entendido como questão nacional, fazendo com que agentes desse campo fizessem parte da comissão em 1970 e recebessem uma parcela significativa da "explicação" da vitória nos jornais. Dirigentes de clubes comumente manobram suas atuações e influência nos campos esportivo e político, saltando dos cargos dos clubes para cargos políticos, como vimos na posição de Mendonça Falcão, presidente da Federação Paulista de Futebol e deputado estadual, por exemplo, e pode ser visto até os dias atuais. A "tradição" da recepção dos governantes aos jogadores e comissão e, principalmente, no encontro entre os dois "comandantes", treinador e político, exemplifica essa interação duplamente amistosa e cooperativa. Com a simbologia que o futebol e, principalmente a seleção, adquiriram no período estudado, manter as relações amigáveis com essa esfera se torna um ingrediente fundamental para que os jornais mantenham uma imagem "positiva" do treinador.

O ser político era um fator importante no "perfil" projetado para o técnico. Saldanha foi "político de menos" e Zagallo "político demais"? Na conjuntura pré Copa de 1970, independente das qualidades exigidas no campo esportivo de cada um, eles jogaram o jogo político de diferentes formas, exemplificando como essa interação não só sustentava as ações do treinador, como também as tutelava. Assim, o "ser treinador" nas relações com a política, também se torna um "ser político", no sentido de captar as movimentações desses dois campos e manejar seu capital simbólico, com o objetivo de se manter no cargo pelo maior tempo possível, se cercando de proteção, no caso de derrotas, e de uma concessão a determinados agentes do campo político de uma parcela considerável da vitória quando ela ocorria.

27 O primeiro número entre parênteses expressa a quantidade de notícias sobre a seleção e o segundo, as reportagens sobre o treinador. 


\section{REFERÊNCIAS BIBLIOGRÁFICAS}

A NOITE. Rio de Janeiro, 24 mai - 30 mai, 1934.

A NOITE. Rio de Janeiro, 05 jun - 12 jul, 1938.

A NOITE. Rio de Janeiro, 13 jul - 30 jul, 1930.

A NOITE. Rio de Janeiro, 24 jun - 23 jul, 1950.

ARAÚJO DE MOURA, Gisella. O Rio corre para o Maracanã. Rio de Janeiro: FGV, 1998.

BOBBIO, N.; MATTEUCCI, N.; PASQUINO, G. Dicionário de política. 4ª ed. Brasília: EDUnB, 1992.

BORDIEU, Pierre. Coisas ditas. São Paulo: Brasiliense, 2004.

BRANDÃO, Gildo Marçal. Linhagens do pensamento politico brasileiro. São Paulo: Aderaldo e Rothschild, 2007.

BRINATI, Francisco. Maracanazo e Mineiratzen: Imprensa e Representação da Seleção

Brasileira nas Copas do Mundo de 1950 e 2014. Curitiba: Prismas, 2016.

CALDAS, Waldenyr. Pontapé Inicial. Ibrasa, 1990.

CARTER, Neil. The football manager: a history. Routledge, 2006.

COSTA, Maurício da Silva Drumond. Os gramados do catete: Futebol e Política na Era Vargas (1930-1945). In: SANTOS, Ricardo Pinto e DA SILVA, Francisco Carlos Teixeira. Memória Social dos esportes. Futebol e política: a construção de uma identidade nacional. Rio de Janeiro: Mauad, 2006.

DIÁRIO DE PERNAMBUCO. Recife, 05 jun - 12 jul, 1938.

FICO, Carlos. Além do golpe: a tomada do poder em 31 de março de 1964 e a ditadura militar. 3aEd. Rio de Janeiro: Record, 2014.

FOLHA DA MANHÃ. São Paulo, 24 mai - 30 mai, 1934

FOLHA DA MANHÃ. São Paulo, 30 mai - 19 jun, 1962.

FOLHA DA MANHÃ. São Paulo, 13 jul - 30 jul, 1930.

FOLHA DA MANHÃ. São Paulo, 05 jun - 12 jul, 1938.

FOLHA DA MANHÃ. São Paulo, 24 jun - 23 jul, 1950.

FOLHA DA MANHÃ. São Paulo,15 jun - 04 jul, 1954.

FOLHA DA MANHÃ. São Paulo, 07 jun - 04 jul, 1958.

FOLHA DA MANHÃ. São Paulo, 12 jul - 26 jul, 1966.

FOLHA DA MANHÃ. São Paulo, 03 jun - 25 jun, 1970.

GASTALDO, Édison. Pátria, chuteiras e propaganda: o brasileiro na publicidade da Copa do Mundo. Annablume, 2002.

GOFFMAN, Erving. Os quadros da experiência social: uma perspectiva de análise. Trad. Gentil A. Titton. Petrópolis: Vozes, 2012.

GUEDES, Simoni Lahud. O Brasil no campo de futebol: estudos antropológicos sobre os significados do futebol brasileiro. EdUFF, 1998. 
GUTERMAN, Marcos. O futebol explica o Brasil: uma história da maior expressão popular do país. São Paulo: Contexto, 2009.

HELAL, Ronaldo. Mídia, construção da derrota e o mito do herói. In: HELAL, Ronaldo, SOARES, Antonio Jorge e LOVISOLO, Hugo. A invenção do país do futebol: mídia, raça e idolatria. Rio de Janeiro: Mauad, 2001.

JORNAL DO BRASIL. Rio de Janeiro, 30 mai - 19 jun, 1962.

JORNAL DO BRASIL. Rio de Janeiro, 15 jun - 04 jul, 1954.

JORNAL DO BRASIL. Rio de Janeiro, 07 jun - 04 jul, 1958.

JORNAL DO BRASIL. Rio de Janeiro, 12 jul - 26 jul, 1966.

JORNAL DO BRASIL. Rio de Janeiro, 03 jun - 25 jun, 1970.

KOSELLECK, Reinhart. Uma história dos conceitos: problemas teóricos e práticos. In: Revista Estudos Históricos. Rio de Janeiro, v. 5, n. 10, p. 134-146, jul. 1992. ISSN 2178-1494. Disponível em: <http://bibliotecadigital.fgv.br/ojs/index.php/reh/article/view/1945/1084>. Acesso em: 23 Jan. 2017.

LEVER, Janet. A loucura do futebol. In: Record. Rio de Janeiro, 1983.

MELO, Victor Andrade de. et al. Pesquisa Histórica e história do esporte. Rio de Janeiro: 7 letras, 2013.

MOSCA, Gaetano. História das doutrinas políticas desde a antiguidade. 3. ed. Rio de Janeiro: Jorge Zahar, 1975.

MOSTARO, Filipe Fernandes Ribeiro. Os técnicos, os campos e as Copas: Imprensa, narrativas e o imaginário da elite cultural do futebol. Disponível em: http://www.bdtd.uerj. br/tde_busca/arquivo.php?codArquivo=15579. Acesso em: 09 out. 2021.

MOSTARO, Filipe Fernandes Ribeiro. Paulistas x Cariocas: as Batalhas Narrativas nos Jornais durante a Copa de 1930. In: IV Encontro Regional Sudeste de História da Mídia 2016, 2016, Niterói. IV Encontro Regional Sudeste de História da Mídia 2016. Niterói: ALCAR, 2016.

MOTTA, Luiz Gonzaga. Análise Crítica da Narrativa. Brasília: Editora Universidade de Brasília, 2013.

O GLOBO. Rio de Janeiro, 24 mai - 30 mai, 1934.

O GLOBO. Rio de Janeiro, 30 mai - 19 jun, 1962.

O GLOBO. Rio de Janeiro, 13 jul - 30 jul, 1930.

O GLOBO. Rio de Janeiro, 05 jun - 12 jul, 1938.

O GLOBO. Rio de Janeiro, 24 jun - 23 jul, 1950.

O GLOBO. Rio de Janeiro, 15 jun - 04 jul, 1954.

O GLOBO. Rio de Janeiro, 07 jun - 04 jul, 1958.

O GLOBO. Rio de Janeiro, 12 jul - 26 jul, 1966.

O GLOBO. Rio de Janeiro, 03 jun - 25 jun, 1970.

PERDIGÃO, Paulo. Anatomia de uma derrota. Rio de Janeiro: L \& PM Editores, 1986. 
PRONI, Marcelo Weishaupt. A metamorfose do futebol. Universidade Estadual de Campinas, Instituto de Economia, 2000.

SARMENTO, Carlos Eduardo Barbosa. A construção da nação canarinho: uma história institucional da seleção brasileira de futebol, 1914-1970. Rio de Janeiro: Editora FGV, 2013. SOUZA, Denaldo Alchorne. O Brasil entra em campo! Construções e reconstruções da identidade nacional (1930-1947). São Paulo: Anablume, 2008.

SOUZA, Jessé. A tolice da inteligência brasileira: ou como o país se deixa manipular pela elite. São Paulo: LeYa, 2015.

WAGG, Stephen. The football world: a contemporary social history. Harvester Press, 1984. 